\title{
Gene editing in bacteria by CRISPR-Cas9 via SpCas9/sgRNA ribonucleoprotein complexes
}

\author{
Arroyo-Olarte Rubén Darioํㅜ, Bravo Rodríguez Ricardo ${ }^{1}$, Morales-Ríos Edgar1* \\ 1Departamento de Bioquímica, Centro de Investigación y Estudios Avanzados, Instituto \\ Politécnico Nacional, Ciudad de México, México \\ *Corresponding author: edgar.morales@cinvestav.mx
}

The authors have withdrawn this manuscript due to a duplicate posting of manuscript number 449263. Therefore, the authors do not wish this work to be cited as reference for the project. If you have any questions, please contact the corresponding author. 